\title{
La revolución silenciada. Hábitos de lectura y pedagogía política en el Perú, 1790-1814
}

\author{
Víctor Peralta \\ Universidad Antonio de Nebrija, Madrid
}

\begin{abstract}
Este estudio se concentra en perfilar la vinculación existente entre la formación del hábito de la lectura, la creación de una opinión pública y la generación de una pedagogía política en el virreinato peruano entre 1790 y 1814. A través de un análisis de la prensa y los libros editados en esta coyuntura, se muestra cómo en Lima el interés por la lectura política va progresivamente desplazando a la lectura de tipo religioso a principios del siglo $X I X$. Se considera que un acontecimiento fundamental que explica esta transformación es el año 1808, cuando en la metrópoli se produce la invasión francesa. La efervescencia de este interés por la política en la población limeña se interrumpe en 1814, al restaurarse en España el absolutismo.
\end{abstract}

El estudio del libro y del hábito de leer en Lima a fines del siglo XVIII y principios del siglo XIX ha despertado poco interés, con la excepción de los clásicos estudios de José Toribio Medina y Rubén Vargas Ugarte. ${ }^{1}$ Asimismo, los análisis concentrados en la evolución de la prensa durante la misma época muestran poco interés en el tema de la lectura, al concentrarse exclusivamente la mayoría en el desmontaje del contenido ideológico de los mismos. ${ }^{2}$ En consecuencia, ninguna de estas perspectivas se ocupa de determinar el impacto que la lectura tuvo en la transformación de la opinión pública casi al finalizar la dominación española.

Si bien la lectura de libros y periódicos en el Virreinato se vio limitada por la censura y por el alto grado de analfabetismo de la población, estos escollos no lograron impedir el surgimiento de espacios, tanto legales como clandestinos, que propiciaron el desarrollo de la lectura. Entre 1790 y 1814 , varias circunstancias políticas permitieron que se produjera en Lima un encuentro entre el hábito de lectura, la formación de una corriente de opinión en la sociedad y la generación de una pedagogía política.

1 Medina, José Toribio: La Imprenta en Lima (1584-1824). 4 vols. Santiago de Chile, 1904. Vargas Ugarte, Rubén: Impresos Peruanos. Lima, 1954.

2 Porras Barrenechea, Raúl: "El periodismo en el Perú: 130 años de periódicos (1791-1921)" en Mundial, Lima, 28 de julio de 1921. Miró Quesada Laos, Carlos: Historia del Periodismo Peruano. Lima, 1957. Macera, Pablo: "El periodismo de la independencia" en Trabajos de Historia, vol. 2. Lima, 1977. Martínez Riaza, Ascensión: La Prensa Doctrinal en la Independencia de Perú, 1811-1824. Madrid, 1985. Villanueva, Carmen: El Peruano y la libertad de imprenta (1811-1812). Lima, Tesis PUC, 1968 (inédito). Dunbar Temple, Ella: "El Investigador, periódico de 1813 a 1814" en El Periodismo en la época de la Emancipación Americana. Lima, 1936. 


\section{Despotismo ilustrado y opinión pública literaria}

Pablo Macera ha calculado que a fines del siglo XVIII menos del $20 \%$ de los habitantes de Lima, comprendidos dentro de la primera edad escolar, recibían instrucción elemental. ${ }^{3}$ Ello significaba que, potencialmente, poco más de mil personas tenían el privilegio de aprender a leer y escribir. Los más favorecidos con esa situación fueron los miembros de la alta aristocracia, debido a que disponían de escuelas privadas como la de Negreiros o el prestigioso Colegio de San Carlos, lugar este último al que sólo se ingresaba después de probar limpieza de sangre. Más abajo en la escala social, los hijos de los comerciantes y de los empleados públicos, contaban con los Colegios Mayores y los conventos para acceder a la instrucción. Aunque la alfabetización estuvo ligada tanto a la nobleza española y criolla como a los sectores de medianos recursos, sólo la primera pudo permitirse el hábito de una lectura continuada. Esto se debió principalmente a dos factores. Primero, al alto costo del libro y, luego, a la férrea censura gubernativa que redujo el número de lectores a aquellos que detentaban importantes cargos públicos civiles y eclesiásticos.

En la última década del siglo XVIII, la posibilidad de ampliar el espacio de la lectura al resto de la aristocracia limeña se materializó dentro de los cafés, ambientes públicos originalmente destinados a la recreación. En 1771 se instaló en Lima el primer café público y hacia 1788 existían seis establecimientos de este tipo. La aristocracia introdujo a principios de la década de 1790 la moda de acudir a estos establecimientos a leer y comentar los periódicos. A esa transformación contribuyó la salida casi simultánea del Diario Erudito de Lima, El Mercurio Peruano y El Semanario Crítico. El Mercurio Peruano resaltó con entusiasmo los cambios que en aquellos "seis recreos inocentes" comenzaba a propiciar la lectura de la prensa:

“(...) los cafés no han servido en Lima mas que para almorzar y ocupar la siesta: las discusiones literarias empiezan ya a tener lugar en ellos. El Diario Erudito y el Mercurio subministran bastante pábulo al criterio del público. ¡Dichosos nuestros papeles, si por medio de la crítica misma que sufran, conservan los cafés libres de las cábalas y murmuraciones, que en otras partes abrigan, y por ventura no se han deslizado en los nuestros!". ${ }^{4}$

3 Macera, Pablo: "Noticias sobre la enseñanza elemental en el Perú durante el siglo XVIII" en Trabajos de Historia, t. II. Lima, 1977, pág. 258.

4 "Idea de las Diversiones Públicas de Lima" en Mercurio Peruano; Lima, 13 de enero de 1791, pág. 29. 
Al igual que los cafés, el auge relativo de las librerías públicas y particulares fue otra prueba de la innovación del espacio público limeño. Hasta mediados del siglo XVIII, por lo general eran las imprentas las que se encargaban de vender los libros. Algunos impresos, como los almanaques y guías de forasteros, podían encontrarse también en las boticas y en los cajones de Ribera ubicados cerca del Cabildo. Esta costumbre se interrumpió en 1763, con la creación de la primera librería especializada de Lima situada en la Calle de Palacio. Paralelamente, el fraile Diego Cisneros abrió un establecimiento similar conocido como la librería del Padre Jerónimo. En este local podían encontrarse libros importados de Europa que, por las poderosas influencias de Cisneros en las esferas de gobierno, no habían sido revisados; hecho que, a su vez, le permitió a Cisneros el abastecimiento de las bibliotecas de importantes personajes públicos como Rodríguez de Mendoza, Bermúdez y Arris. ${ }^{5}$ En 1798 la librería de la calle de Palacio fue reemplazada por otra que fundó el impresor Guillermo del Río. Al terminar la centuria se formó otro puesto particular de venta de libros en frente de la calle del Espíritu Santo.

A fines del siglo XVIII, Lima contaba con bibliotecas particulares de relativa importancia. Las bibliotecas más renombradas estuvieron en poder de los conventos religiosos. La de mayor importancia, la biblioteca de los jesuitas, se estimó contaba con unos treinta y cinco mil volúmenes. En 1798 se contabilizaron siete mil volúmenes en la biblioteca del Convento de San Francisco. ${ }^{6}$ En la biblioteca de la Universidad de San Marcos existía también una cantidad apreciable de obras literarias, jurídicas y políticas pero, a diferencia de las religiosas, el lugar permaneció cerrado y no se pudo consultar sino hasta después de la independencia. Sólo los prebendados, canónigos y empleados de la alta burocracia colonial estaban autorizados a tener en sus bibliotecas libros de carácter histórico, literario y científico. La mayoría de estas bibliotecas no sobrepasaban los doscientos volúmenes y, casi sin excepción, todas respetaron la orden oficial de no adquirir las obras filosóficas y políticas reprobadas por el gobierno y perseguidas por la Inquisición. ${ }^{7}$ $\mathrm{Al}$ inventariarse las dos más importantes bibliotecas particulares de fines del siglo XVIII, la del cosmógrafo Cosme Bueno y la del oidor Echeveriz, con más de mil volúmenes cada una, no se halló ninguna obra política censurada.

5 Barreda y Laos, Felipe: Vida Intelectual del Virreinato del Perú. Lima, 1964, págs. 222-223.

6 Macera, Pablo: "Bibliotecas Peruanas del siglo XVIII" en Trabajos de Historia, t. 1, Lima, 1977, pág. 298.

7 Apuntes históricos del General Manuel Mendiburu. Lima, 1906, pág. 72. 
Pese a la moda de los cafés, el aumento de las librerías y la existencia de bibliotecas particulares fue imposible la generación de una corriente de opinión extra-literaria en Lima, tal como se produjo en México o en Buenos Aires. ${ }^{8}$ Su explicación está en que la principal dificultad seguía siendo la censura gubernamental impuesta a la difusión de la lectura profana. Al comenzar la década de 1790, aún seguían estando vigentes los dispositivos de censura de la Recopilación de 1681. Estaba prohibida en todo el virreinato la lectura de libros de romance "que traten de materias profanas, fabulosas y historias fingidas, porque se siguen muchos inconvenientes, por lo que mandamos a los virreyes, Audiencias y gobernadores que no los consientan imprimir, vender, tener ni llevar a sus distritos, y provean que ningún español ni indio lo lea". ${ }^{9}$ En Lima no se podía imprimir ni transportar obra alguna sin una previa licencia otorgada por los Consejos de Castilla e Indias. Se requería, además, de otra licencia especial para venderlos. A pesar de la rigidez de estas trabas, la normativa de controlar la lectura no colmó el desmedido afán de algunas autoridades por limitar al máximo la difusión de ciertos escritos. Las célebres prohibiciones impuestas sobre la lectura de Los Comentarios Reales, de Garcilaso Inca de la Vega, y El Elogio al Virrey Jáuregui, de José Baquijano y Carrillo, fueron dos ejemplos del exagerado recelo esgrimido por parte de las autoridades.

En ese contexto, la ocupación predilecta de las tertulias limeñas fue fomentar la discusión literaria en grupos selectos y con previo acuerdo de las autoridades. Se sabe que en 1785, José María Egaña animaba una de esas primeras tertulias, que se reunía en su domicilio, con el propósito de entretenerse, practicando la lectura y la meditación. Dos años después, el mismo Egaña se integró a otra tertulia denominada Academia Filarmónica, y en la que participaban siete miembros, entre los que destacaban Hipólito Unanue, José Rossi y Rubí y José Baquijano y Carrillo. Dicha tertulia tenía entre una de sus peculiaridades el contar para la discusión con la presencia de tres mujeres. El reglamento de la Academia Filarmónica dado a conocer a las autoridades indicaba, con claridad, que en sus discusiones "sólo se trataba de materias literarias y se examinaban las noticias públicas".

La Academia Filarmónica, luego de disolverse, volvió a reintegrarse a fines de 1790 en una tertulia compuesta de cinco integrantes. Esta tertulia, autodenominada Sociedad de Amantes del País, optó por traspasar el

8 Guerra, Francois-Xavier: Modernidad e Independencias. México, 1993, págs. 92-98.

9 Medina, José Toribio: Historia de la Imprenta en los Antiguos Dominios Españoles de América y Oceanía, t. 1. Santiago de Chile, 1958, pág. 492. 
espacio privado en que proyectaban sus discusiones, a través del proyecto de publicar un papel periódico. La Sociedad decidió aprovechar la coyuntura abierta por la legislación de prensa dada en la metrópoli en 1788, que permitía la publicación de papeles siempre y cuando no se pusieran en ellos "expresiones torpes ni lúbricas, y tampoco sátiras de ninguna especie, ni aun de materias políticas, ni cosas que desacrediten las personas, los teatros e instrucción nacional". ${ }^{10}$ En el prospecto donde se anunció la salida del Mercurio Peruano, Jacinto Calero y Moreira aseguró que el periódico nacía con el exclusivo fin de fomentar el conocimiento de la Historia, la Literatura y las noticias públicas, para ampliar y perfeccionar "los asuntos interesantes a la vida sociable". Lanzado en enero de 1791, bajo la protección del virrey Gil de Taboada, el Mercurio Peruano llegó a alcanzar la cifra de las cuatrocientas suscripciones.

El interés por impulsar la ilustración con la creación de tertulias de salón dedicadas a la práctica de lectura, se convirtió en una nueva moda de la aristocracia limeña. En mayo de 1791 el Mercurio dio cuenta de la formación de una Tertulia Poética, animada por Hipólito Unanue, e integrada por diez miembros. En marzo de 1794 el número de socios académicos de la Sociedad de Amantes del País se había elevado a veintiuno. Pese a prohibirlo sus reglamentaciones, estas tertulias no pudieron evitar el abordaje del tema de la política, motivadas primero por el desarrollo de la revolución francesa y más tarde por el estallido de la guerra entre Francia y España.

En su estudio sobre la vida intelectual del virreinato, José Barreda y Laos halló que sólo dos artículos del Mercurio Peruano recogían cierta sensibilidad por la política. Se trata de la "Disertación histórica de Meligario sobre el hospicio de pobres en Lima" y de la "Defensa de los derechos de los negros bozales", escritos ambos donde se expresaba "alguna intención de regeneración social". ${ }^{11}$ Existe, sin embargo, una prueba de que en la tertulia de los Amantes del País se discutía el significado político de la libertad y la democracia que proclamaban los revolucionarios franceses y norteamericanos. Esta es la "Carta escrita a la Sociedad sobre el abuso de que los hijos tuteen a sus padres", que trae comentarios bastante relevantes sobre el significado que para Lima podría conllevar el arribo de tales ideas políticas modernas. El relato comienza cuando Eustachio Phylomathos, ausente por siete meses de su hogar, retorna a ella y nota un cambio en la

10 González Palencia, Angel: Estudio Histórico sobre la Censura Gubernativa en España, 1800-1833. vol. 1; Madrid, 1934, pág. XXXI.

11 Barreda y Laos: Vida Intelectual del Virreinato..., pág. 226. 
conducta de su hijo y sus tres hijas: "oí que todas estas criaturas me trataban de Tú". Al preguntar a su esposa las razones de tal novedad, ella le responde que mientras estuvo ausente los cuatro "habían estado en casa de Democracia su madre durante mi ausencia, y que allí les habían enseñado lo que es común en todas las clases de ciudadanos". Phylomathos, desolado, halló un consuelo al indagar que la misma costumbre del tuteo se había extendido a otras familias limeñas. Pero un día, intentando corregir en su hogar a sus hijos, Phylomathos recibió una reprimenda de Democracia:

“(...) bien se conoce que Vmd. no quiere a sus hijos, y que más bien es tirano de ellos que padre: Vmd. que quiere enseñar a otros la buena crianza, debe saber primero, que es mucho atrevimiento el querer corregir una costumbre general; y que aunque no lo fuera es mi voluntad, y basta para que sus hijos tuteen a quien les dé la gana".

Phylomathos concluye rogando al editor que se pregunte a todas las damas de Lima que piensan como Democracia que "si nuestro idioma tiene los tratamientos confidenciales con separación de los de reverencia, ¿por qué los hemos de confundir? ¿por qué hemos de acostumbrar a los hijos a que hablen a su madre en el mismo tono que a su esclava, y a que no distingan a su padre de su calesero?". ${ }^{2}$ De estas cuestiones se desprende que lo que el autor de la "Carta escrita a la Sociedad" encontraba cuestionable en la sociabilidad propuesta por los partidarios de la democracia era una igualdad que conducía a perder el respeto a la autoridad. La moraleja implícita era que sin una sumisión cotidiana al poder, el armazón de todo el cuerpo social corría el riesgo de debilitarse. La reflexión concluía en una explícita apología del despotismo ilustrado.

Los dos ejemplos anteriores muestran cómo el discurso del Mercurio Peruano estuvo rodeado de una retórica de respeto absoluto a la autoridad política virreinal. Los Amantes del País sabían que su aporte al conocimiento de los tiempos sería, tarde o temprano, objeto de un pronto reconocimiento oficial. Como las sociedades de amantes que se formaron en España, la peruana también aguardaba el otorgamiento de prebendas personales ofrecidas por su protector, el virrey Gil de Taboada. Éste, al remitir ejemplares del Mercurio Peruano al rey, fue muy claro en señalar que todos ellos se habían ganado el derecho de acceder a cargos importantes dentro de la administración. La ilustración y el utilitarismo de la Sociedad de Amantes del País tuvo por fin su recompensa en 1794. Ese año, José

12 Mercurio Peruano; Lima, 16 de enero de 1791, págs. 37-38. 
Baquijano y Jacinto Calero fueron promovidos por el gobierno para continuar su carrera pública en España. Mientras tanto, José Rossi y Rubí, también decidía el mismo año emprender el retorno a Madrid para ocuparse de negocios personales. De todos ellos, fue Baquijano quien más réditos obtuvo, al cumplirse su propósito de ver restituido su crédito público, herido por la circulación del Elogio a Jáuregui.

El viaje de Baquijano, Calero y Rossi y Rubí dejó al Mercurio Peruano sin sus principales animadores. La edición de 1795 fue asumida por el fraile Diego Cisneros, pero la pérdida de lectores motivó su suspensión definitiva. Con el fin de esta publicación, desapareció el último bastión de la corriente literaria limeña ya que, unos años antes, habían dejado de circular el Diario Erudito y el Semanario Crítico. La experiencia del proyecto ilustrado se encaminó a su fin con la partida del virrey Gil de Taboada. En efecto, el gobierno de Ambrosio de O'Higgins terminó con la era de los virreyes ilustrados. El nuevo mandatario actuó bajo la consigna de la metrópoli de evitar a toda costa la entrada de ideas extranjeras en el Virreinato. Acogiéndose a tal disposición, el gobierno perdió todo interés en las tertulias. Tales reuniones, asimismo, se hicieron escasas al acatar la aristocracia dócilmente el mandato de la autoridad. La publicación de $L a$ Gaceta de Lima, entre 1794 y 1799, cuyos editores fueron los ex-mercuristas José de Egaña e Hipólito Unanue, no alcanzó ninguna resonancia debido a que ambos sólo transcribían las noticias que publicaba El Diario de Madrid sobre la corte española. De otro lado, se hizo cotidiano el registro de todos los establecimientos donde se vendían libros y podía ejercerse la lectura. Debido a esa persecución, en 1796, el que fuera último editor del Mercurio Peruano, el padre Cisneros, fue denunciado por la Inquisición al hallársele libros prohibidos tanto en su biblioteca como en su librería.

El siglo XVIII llegó a su fin con la salida de un nuevo periódico oficial de esporádica aparición e intrascendente como lectura: El Telégrafo Peruano. El gobierno apenas toleraba la lectura de obras religiosas, que es lo único que las imprentas estaban autorizadas a editar. Todo esto no evitó que el público lector adquiriera un nuevo hábito: la consulta de la prensa extranjera que arribaba por los puertos. El comercio libre se convirtió en la vía de entrada de una lectura que, aunque con atraso, suplió la ausencia de información. La aristocracia limeña encontró pronto en la subscripción a tales papeles un sustituto a la temporal ausencia de diarios locales.

La lectura de periódicos extranjeros a principios del siglo XIX contribuyó a formar una corriente de opinión política fuera del control del 
gobierno. ${ }^{13} \mathrm{El}$ virrey, que en un principio confesó no haberle preocupado la circulación de tales diarios por considerarlos inofensivos, muy pronto cambió de parecer al advertir el peligro de una lectura que podía afectar la seguridad del virreinato. En abril de 1799, O'Higgins informó al secretario de Estado español que había visto correr en manos de los vecinos de Lima muchos periódicos ingleses, franceses y norteamericanos "en que se veían y leían especies que era por demás llegasen al conocimiento del pueblo". ${ }^{14}$ O'Higgins, presuroso, publicó un bando dirigido a todos los habitantes de la capital para que entregaran al gobierno dichos papeles. No obstante, esa medida no logró impedir que la lectura llegara ahora a sectores de la aristocracia cada vez más difíciles de controlar. La opinión pública limeña se había ampliado y, con ello, crecía el peligro de que la lectura política llegara a capas de la población habituadas hasta entonces a una total sumisión a la autoridad.

\section{El Fidelismo y la creación de una corriente de opinión política}

Al comenzar el siglo XIX, la lectura clandestina del libro fue un atributo que la aristocracia comenzó a compartir con otros sectores socialmente más bajos. Prueba de ello son los oficios de los lectores descubiertos y denunciados ante el Tribunal del Santo Oficio. En 1800, el aristócrata Antonio Álvarez del Villar fue acusado por la Inquisición por tener un libro impreso en Paris titulado La Europa Política. También fue denunciado ese mismo año el asentista de la casa de comedias, Andrés Maza, junto con Agustín Landáburu, por leer "malas obras". En 1803, se abrió un proceso contra Francisco Gaviria y cien personas más por sospecharse que habían leído las Cartas de Eloísa y Abelardo.$^{15}$ El gobierno del virrey Avilés, asimismo, amplió dicha persecución a los extranjeros. El virrey identificó a estos últimos como los instigadores de las lecturas prohibidas que proliferaban en Lima. El 19 de noviembre de 1801, el Tribunal del Santo Oficio, hizo una advertencia al barón de Nordenflicht "que aun cuando permaneciese en el día en la religión luterana, no tenía licencia ni estaba autoriza-

13 Sobre la importancia de la lectura de los periódicos extranjeros en Francia en vísperas de la revolución de 1789, Popkin, Jeremy D.: Revolutionary News. The Press in France, 1789-1799. Duke, 1990, págs. 20-21.

14 Archivo General de Indias (en adelante AGI), Estado, Lima, 1, núm. 88.

15 Palma, Ricardo: Anales de la Inquisición de Lima. Buenos Aires, 1959, págs. 330-333. 
do a prestar a nadie libros prohibidos" ${ }^{16}$ Por la misma causa fue denunciado José Joaquín de Olmedo, quien entonces estudiaba en el Convictorio de San Carlos, por tener libros prohibidos y prestarlos a sus condiscípulos.

En marzo de 1805, España puso en vigencia un nuevo reglamento de imprenta para la circulación de libros y prensa, con el que se pretendió hacer más eficiente el control de las ideas difundidas por la revolución francesa. Dicho reglamento introdujo la figura del juez de Imprenta, que vino a reemplazar al Consejo de Castilla e Indias en la censura y el otorgamiento de licencias tanto en España como en América. ${ }^{17}$ En Lima, el Tribunal del Santo Oficio quedó encargado de enviar las listas de censuras a la nueva instancia metropolitana. Lo sorprendente de todo ello fue que de todas las denuncias, ninguna ocurrió por leer a un revolucionario francés. Los acusados fueron lectores a quienes se sorprendió consultando comedias teatrales como El Renegado de Francia o comentando La Henriada y El Jairo de Voltaire. ${ }^{18}$

El registro de los establecimientos sospechosos de propiciar lecturas prohibidas prosiguió en toda la ciudad al amparo de la nueva ley de imprenta. El Gobierno y la Inquisición coordinaron esfuerzos para hacer continuas requisas en las librerías privadas así como en los cajones de Ribera. La persecución del libro se amplió a la misma aduana del Callao, donde no se permitió la entrada de ningún bulto sin haber pasado previamente un riguroso control. ${ }^{19}$ Sólo los cafés se libraron de la persecución gubernamental. Los cafés continuaron siendo los espacios predilectos del esparcimiento de las capas altas y medias, aunque de vez en cuando los lectores acudían allí para "ocuparse de novedades y sostener conversaciones sobre las materias que llamaban la pública atención" ${ }^{20}$ Era cotidiana la lectura en los cafés de $E l$ Telégrafo Peruano, un periódico que — - según confesión de su editor - tuvo por propósito ocultar la "explosión de la revolución francesa (que) bamboleó el espíritu de los hombres, y dio un extraordinario impulso a su curiosidad". ${ }^{21}$ Entre 1800 y 1805, la censura gubernativa fue tan estricta que, incluso, se prohibió publicar poesía para evitar que se deslizaran de su lectura interpretaciones políticas. ${ }^{22}$

16 Torre Revello: El Libro, la Imprenta y el Periodismo..., pág. 132.

17 González Palencia: Estudio Histórico sobre la Censura Gubernativa..., pág. XVII.

18 Palma: Anales de la Inquisición..., pág. 336.

19 Torre Revello: El Libro, la Imprenta y el Periodismo..., pág. 117.

20 Mendiburu: Apuntes Históricos..., págs. 79-81.

21 El Peruano, núm. 15; Lima, 25 de octubre de 1811.

22 González Palencia: Estudio Histórico sobre la Censura Gubernativa..., págs. XXXII-XXXIII. 
En marzo de 1805, Guillermo del Río es autorizado por el gobierno a reemplazar el intrascendente El Telégrafo Peruano por la Minerva Peruana. El cambio de título anunció una innovación más trascendental. El reinicio en 1804 de la guerra entre España e Inglaterra hizo que el virrey se viera en la necesidad de auspiciar la prensa oficial como un medio para promover la causa española. También se esperaba que con la suscripción al periódico se podría contribuir al sostenimiento de la causa. Ambas fueron las razones que movieron al virrey Avilés a autorizar que la Minerva Peruana se convirtiera "en un delicado y sazonado ambigú, con el fin principal de combatir las preocupaciones, y romper la densa tela de la ignorancia que cubría su dilatado hemisferio". ${ }^{23}$ Por vez primera el público limeño tuvo en sus manos, al lado de órdenes reales, decretos oficiales y notas de carga, una información continua sobre el desarrollo del conflicto bélico. La información de la guerra se consiguió por varias vías, unas veces extractándose las gacetas europeas, otras veces recogiéndose la noticia en los navíos llegados de la Península o valiéndose de los correos terrestres. La estructura de noticias se completó con la autorización a Del Río para poder cubrir noticias locales de carácter público como, por ejemplo, la amplia cobertura que se dio a la introducción de la vacuna contra la viruela entre la población limeña.$^{24}$

La Minerva Peruana, bajo el gobierno del virrey Fernando de Abascal, superó la cifra de subscriptores establecida por el Mercurio Peruano al alcanzar los quinientos. Para Guillermo del Río el secreto de la demanda de su diario estaba en haber intuido lo que el público deseaba ver publicado. El editor hallaba en la variedad de la noticia, el entretenimiento y la propaganda fidelista las causas del incremento de lectura de la Minerva Peruana. Más adelante, la fama del diario oficial se acrecentó al especializarse éste en el arte de convertir el rumor en noticia. El uso propagandístico del rumor caló hondo en el gusto de los lectores. Esta práctica de fabricar la noticia se haría común, sobre todo, después de producirse la invasión francesa. Por ejemplo, el editor de la Minerva Peruana se encargó de alimentar el rumor popular del triunfo de la alianza hispano-francesa, y de la caída del despótico príncipe de la Paz, propalándose en el diario que Fernando VII marchaba a Francia a hacerle una visita de agradecimiento a Napoleón Bonaparte. ${ }^{25}$

23 El Peruano, núm. 15; Lima, 25 de octubre de 1811.

24 Minerva Peruana, núm. 41; Lima, 19 de noviembre de 1805 y núm. 42; Lima, 27 de noviembre de 1805 .

25 Ibídem, núm. 39; Lima, 31 de agosto de 1808. 
Hasta octubre no suspendió la Minerva Peruana este tipo de noticias al recibir informes que confirmaban la invasión francesa.

El inicio de una retórica política anti-napoleónica a través de la Minerva Peruana se convirtió en el medio más recurrido por Abascal para sostener el fidelismo en Lima. ${ }^{26}$ Fue ésta la primera vez en que un diario de la colonia hacía uso de la propaganda política. En diciembre de 1808, junto con el arribo de una fragata procedente de Valparaíso llegó el rumor de que todo el ejército francés había sido derrotado. En Lima, a la orden de repique general e iluminación de los edificios públicos, siguió una edición extraordinaria de la Minerva Peruana totalmente dedicada a resaltar el triunfo y "las glorias de la metrópoli". ${ }^{27}$ Dicha noticia se desvaneció semanas después al conocerse la capitulación de Madrid, hecho que Del Río puso en conocimiento de la población limeña en la edición del 20 mayo de 1809. En septiembre se anunció que con el triunfo de la resistencia española en Cuesta "nuestra península está ya casi enteramente libre de la peste napoleónica". ${ }^{28} \mathrm{Al}$ poco tiempo, sin embargo, llegaron las noticias del desastre del ejército español en Sevilla, con lo que los lectores quedaron convencidos de que el diario limeño no daba una información veraz.

Los lectores de la Minerva Peruana, cansados de sus invenciones políticas, acrecentaron su desconfianza con el contenido informativo del diario oficial. Este imparable desprestigio se tradujo en una alarmante pérdida de subscriptores. Guillermo del Río, intentando revertir el descenso en la lectura de su diario, prometió ser más severo en el uso de sus fuentes:

“(...) continuamente nos vemos inundados de noticias fabulosas, así pues para apreciar y dar un justo valor a ellas, es preciso hacer un cálculo más profundo del que vulgarmente se cree, porque de lo contrario, la mentira se fundirá con la verdad. El medio para no engañarse, es atenerse sólo a lo que dicen las gacetas ministeriales: todos los demás papeles deben leerse con severa crítica y mucha cautela". ${ }^{29}$

Pese a su propósito de enmienda, el periódico siguió publicando triunfos ficticios que luego tuvieron que desmentirse. Se volvió a justificar el lanzamiento de noticias sin fundamento certero, considerando que "nada es

26 El estudio del uso de la retórica política como un lenguaje encargado de reformar las percepciones políticas para reconstituir el mundo social, en Hunt, Lynn: Politics, Culture and Class in the French Revolution. Berkeley, 1986, págs. 19-51.

27 Nieto Vélez, Armando: Contribución a la Historia del Fidelismo en el Perú (1808-1810). Lima, 1960, pág. 109.

28 Minerva Peruana, núm. 66; Lima, 30 de septiembre de 1809.

29 Ibídem, núm. 36; Lima, 26 de mayo de 1810. 
más difícil en las actuales circunstancias que deslindar la realidad de los sucesos, cuando careciendo de noticias de oficio nos hallamos restringidos a las que nos prestan las papeletas, apenas veces dictadas por la opinión, por el deseo, no pocas veces por rumores vagos o forjadas con el fin de engañar o alucinar al público". ${ }^{30}$

Es importante tener en cuenta que la retórica política fidelista no se circunscribió a la Minerva Peruana. La propaganda fidelista invadió también los cafés. El 13 de octubre de 1808, con ocasión de la proclamación y jura de fidelidad a Fernando VII en Lima, en las puertas de todos los cafés se colocaron espontáneamente carteles con la siguiente leyenda "Tenemos rey, queremos jurarlo. Juramos a nuestro rey y señor Fernando VII". ${ }^{31}$ En seguida, fue el propio gobierno el que patrocinó la apertura de estos espacios públicos a la lectura y discusión política, siempre y cuando se usaran para alentar la causa del rey. Las sanciones contra todo aquel que en dichos establecimientos vertiera frases contrarias al fidelismo se hicieron bastante severas. Según el anónimo autor del "Quaderno de varias cosas curiosas", el 12 de julio de 1809 en el café de Bodegones, Francisco Pérez Canosa y José Antonio García fueron sorprendidos hablando mal de la Junta Central, siendo por esa falta "sentenciados a diez años de destierro a un presidio de África uno y otro a Chagres". ${ }^{32}$ Salvo ese incidente, no existen otras evidencias de que los cafés sufrieran clausura por las conversaciones políticas que allí se daban.

El teatro, al igual que los cafés, fue autorizado como espacio de discusión política, al verse su utilización conveniente para difundir la propaganda realista. Fue el propio virrey quien autorizó y asistió a la escenificación de la primera obra de contenido político en un teatro limeño, impresa de inmediato con el titulo de Loa alegórica con que solemniza el teatro de la ciudad de Lima los días de nuestro soberano monarca el señor don Fernando VII, el día 30 de mayo de 1809, por un fiel americano español. ${ }^{33}$ La Minerva Peruana en seguida anunció, en su edición del 22 de julio de 1809, el estreno de otra obra de contenido político en el Teatro Principal titulada Los Patriotas de Aragón. La retórica fidelista no sólo se incluyó en los textos

30 Ibídem, núm. 61; Lima, 11 de septiembre de 1810.

31 Abascal y Sousa, José Fernando de: Memoria de Gobierno. Vicente Rodríguez Casado y José Antonio Calderón Quijano (eds.). vol. 1. Sevilla, 1944, pág. LXXX; Nieto Vélez: Contribución a la Historia del Fidelismo..., pág. 26.

32 Urteaga, Horacio H.: "Un inédito valioso", Revista Histórica, t. II, trimestre III. Lima, 1907, pág. 408. También Nieto Vélez: Contribución a la Historia del Fidelismo..., págs. 102-104.

33 Medina: La Imprenta en Lima, t. III, págs. 393-394. 
teatrales, sino también en los listines de las acostumbradas corridas de toros. Uno de estos programas se titulaba El Toro Maestro e incluía versos donde la valentía española aparecía enfrentada a la perfidia francesa. ${ }^{34}$

La importante innovación política ocurrida en los espacios públicos se completa con el auge de las imprentas. Éstas fueron autorizadas a reeditar las obras políticas de contenido anti-napoleónico escritas en la metrópoli. En 1808 apareció en Lima la primera obra política, sin mención de imprenta ni autor, titulada El Patriota peruano expresándose por todos.$^{35}$ En seguida, la imprenta de Los Huérfanos fue autorizada a editar los Sentimientos de un americano, también de autor desconocido. La imprenta de la calle Bravo, por su parte, puso en venta el folleto Viva Fernando VII. ${ }^{36}$ A la imprenta de los Huérfanos le correspondió imprimir la primera obra poética política: El Árbol, de José Joaquín Olmedo. El público limeño tuvo en sus manos, en 1809, las reimpresiones de la Carta que un español escribe a Murat sobre sus aventuras en España y del Diario Napoleónico de hoy martes, aciago para los franceses y domingo feliz para los españoles. Primer año de la libertad, independencia y dicha española, de la decadencia y desgracia de Bonaparte, del abatimiento de la Francia, salvación de la Europa y último de la tiranía napoleónica.

Un importante cambio en la lectura se observa a partir de 1808 si se compara la cantidad de impresos políticos y religiosos que circulaban en Lima. Entre 1800 y 1807, tan sólo se habían editado unos siete impresos con cierto contenido patriótico, mientras que los religiosos superaban el centenar. Pero en 1808, Lima vivió una explosión de impresos políticos al circular 25 obras de carácter político fidelista, que casi igualaban la publicación de textos religiosos del mismo año. Esta misma relación se mantuvo en los años de 1809 y 1810, con una producción de textos religiosos que a duras penas superaba la apreciable cantidad de impresos políticos. Una revolución silenciosa en la imprenta se había activado a expensas de la lucha gubernamental contra la invasión francesa ${ }^{37}$ La participación de la

34 Odriozola, Manuel de: Documentos Literarios del Perú, t. 10. Lima, 1877, págs. 384-385.

35 Nieto Vélez: Contribución a la Historia del Fidelismo..., pág. 70.

36 Viva Fernando VII. Melpomene Peruana. Rasgo de tierna lealtad producido por amor y fidelidad de un americano con vista de los sentimientos que esparció en esta metrópoli la funesta retención de la augusta persona del Rey nuestro señor en los dominios de la injusta Francia. Lima, 1809. Medina: La Imprenta en Lima..., t. III, pág. 397.

37 Sobre el significado de la imprenta en el fundamental paso de la lectura religiosa a la política, ver Darnton, Robert y Roche, Daniel (eds.): Revolution in Print. The Press in France, 1775-1800. Berkeley, 1989, págs. 3-26. También Chartier, Roger: The Cultural Uses of Print in Early Modern France. New Jersey, 1987, págs. 189-191. 
imprenta en la propaganda fidelista se suspendió a mediados de 1810, al reportarse el pésimo estado de mantenimiento de la mayoría de ellas:

“(...) de quatro que tiene la capital sólo hay una mediocremente servida, y las otras tres inutilizadas y sin esperanza de reponerse con letra de Europa". ${ }^{38}$

\section{LA CIRCULACIÓN DE LA LECTURA EN LIMA}

\begin{tabular}{lcccc} 
& Religiosos & Políticos & Literatura & Periódicos \\
\hline 1800 & 5 & - & 1 & - \\
1801 & 7 & - & 3 & - \\
1802 & 12 & 2 & 5 & - \\
1803 & 7 & - & 2 & - \\
1804 & 10 & - & 1 & - \\
1805 & 13 & 1 & 1 & 1 \\
1806 & 13 & 4 & 1 & 1 \\
1807 & 9 & 4 & - & 1 \\
1808 & 30 & 25 & - & 1 \\
1809 & 24 & 16 & 1 & 1 \\
1810 & 24 & 13 & 1 & 1 \\
1811 & 22 & 27 & 8 & 2 \\
1812 & 21 & 26 & 12 & 5 \\
1813 & 16 & 25 & 13 & 9 \\
1814 & 22 & 29 & 10 & 3 \\
1815 & 23 & 5 & 10 & 1 \\
1816 & 18 & 1 & 16 & 1
\end{tabular}

Fuente: Medina: La Imprenta en Lima, t. IV; Vargas Ugarte, Rubén: Impresos Peruanos, t. III y IV.

Fue en ese momento cuando Abascal hizo pública su intención de relanzar el Mercurio Peruano en cuanto la imprenta quedara rehabilitada. Publicada esta primicia en la Minerva Peruana, ella alentó el deseo del virrey, augurando que en el momento que se lograran fundir nuevos caracteres quedaría "verificado este proyecto y restablecido el papel periódico

38 Minerva Peruana, núm. 41; Lima, 26 de junio de 1810. 
del Mercurio, (con lo cual) se han de circular todos los conocimientos útiles de las ciencias naturales, las artes y la industria". ${ }^{39}$

La estrategia usada por Abascal de patrocinar la difusión de la retórica fidelista se canceló en septiembre de 1810 al llegar a Lima las noticias del asedio a La Paz por los insurgentes bonaerenses. La invasión del Alto Perú por el ejército de la insurgente Junta de Buenos Aires el 14 de septiembre, obligó al virrey a prohibir que en la prensa volvieran a insertarse noticias "extranjeras, ni (de) otros papeles que no estén autorizados en bastante forma por el Gobierno, celando que no se introduzcan los sediciosos de nuestros enemigos" ${ }^{40}$ Cuatro días después, el virrey mandaba encarcelar a Guillermo del Río acusado de participar en la conspiración que tramaba ejecutar el clérigo Ramón de Anchoris. Dicho escándalo tuvo su origen en una polémica entablada entre Del Río y un grupo de rioplatenses sobre el impreso Leales habitantes del Perú, en torno al que se discutía si su autor era o no el deán de Córdoba Gregorio Funes. ${ }^{41}$ El gobierno consideró que estas reuniones no eran sino un pretexto para hacer conversaciones subversivas. De inmediato, Abascal relevó a Guillermo del Río de la edición del periódico oficial. Con esa medida, el fin de la era de la Minerva Peruana vino casi de inmediato. El gobierno anunció la reaparición de la Gaceta del Gobierno de Lima, que quedaba limitada "al extracto de las gazetas de la regencia, reales órdenes y algunos papeles importantes con que les favorece la superioridad". ${ }^{42}$

La vuelta a la situación política vivida antes de agosto de 1808 se extendió a todos los espacios públicos limeños. Abascal, en adelante, vinculó el reforzamiento de su autoridad a la restauración de una férrea censura gubernativa sobre todo escrito y lectura. A las imprentas, por ejemplo, se les prohibió editar nuevas obras políticas. En las funciones teatrales y en los listines de las corridas de toros se proscribió toda alusión a la política. En todos estos casos, el virrey volvió a ampararse en la ley de imprenta de 1805 para controlar la lectura. La persecución oficial se amplió incluso a las "inscripciones subversivas" en pañuelos, sobre todo después de conocerse un informe elevado por la Inquisición al Gobierno el 19 de julio de 1810. El informe dio cuenta del hallazgo de pañuelos con el siguiente

39 Ibídem.

40 Medina: Historia de la Imprenta en América..., pág. 497.

41 Vargas Ugarte, Rubén: Historia del Perú. Emancipación (1809-1825). Buenos Aires, 1958, págs. 20-21.

42 El Peruano, núm. 15; Lima, 25 de octubre de 1811. 
estampado: "Personas, Conciencia y Comercio Libre" ${ }^{43}$ Abascal dispuso que tras borrar de los pañuelos aquellas palabras, éstos se devolverían a sus dueños.

Después de varios meses de un estricto control impuesto sobre lo que la población debía leer, el despotismo de Abascal se vio obligado a ceder tras llegar de la metrópoli la orden que facultaba a los ciudadanos a expresar libremente sus pensamientos e ideas políticas. El 10 de noviembre de 1810, en efecto, las Cortes decretaron la libertad de imprenta que autorizaba la libre publicación y circulación de periódicos y de impresos políticos con el fin de frenar el despotismo. Abascal, contrariado por la noticia, acató la orden al hacer público el decreto el 18 de abril de 1811, suspendiendo su entrada en vigor hasta que no se organizara la Junta de Censura en Lima. Con la libertad de imprenta se produjo el retorno de la retórica fidelista que, esta vez, parecía obligada a ganarse a la opinión pública a partir de su contienda con el discurso antagónico no oficial que la eliminación de la censura permitió surgir.

\section{El liberalismo constitucional y la pedagogía política}

La libertad de imprenta completó la revolución que en este campo ya había propiciado la propaganda fidelista de Abascal. En 1811, por vez primera, la folletería política superaba en cantidad a las publicaciones religiosas. Esta supremacía del impreso político se volvió a repetir en 1812, en 1813 y en 1814. El incremento de las obras políticas durante el interregno liberal no fue, sin embargo, homogéneo como ocurrió hasta antes de 1810. Ahora destacaban, junto a los acostumbrados textos patrióticos de arenga fidelista, los que polemizaban con las disposiciones de las autoridades locales amparándose en la libertad de expresar sus ideas. Esta última postura, apegada al mensaje del constitucionalismo español, fue mucho más radical y expresiva en algunos de los nuevos periódicos no oficiales que comenzaron a editarse. En 1811 sólo un periódico - El Peruano- se adscribía a la nueva tendencia política, sumándosele El Satélite del Peruano en 1812. Con la clausura de ambos periódicos, ordenada por el virrey en julio de 1812 , dicha postura crítica y contestataria a la autoridad quedó silenciada.

43 Medina: Historia de la Imprenta..., pág. 29. 
El 6 de septiembre de 1811, Bernardino Ruiz, junto con Guillermo del Río y Gaspar Rico, decidieron editar El Peruano. Dicho periódico, impreso en la imprenta de los Huérfanos, irrumpió en la esfera pública usando un tono fuera de lo común. El Peruano ofrecía ilustrar a la población en sus derechos de "hombres libres", lo cual era sinónimo de enfrentar el arbitrismo de la autoridad. En esa mira, el periódico prometió a sus lectores convertirse en "un asilo seguro al inocente, y de espada exterminadora para toda especie de delitos, que en tiempos anteriores cometían descarada e impunemente (las autoridades), y que hoy gracias a los principios liberales de las cortes se pueden reclamar y escarmentar con un juicio público ante el tribunal de la opinión pública" ${ }^{44}$ Días después, un lector remitió una carta a los editores, coincidiendo con ellos en que con la lectura de El Peruano los limeños tenían por fin un motivo para abandonar su inacción política:

“(...) esa languidez de sus almas, que hasta el día los ha hecho mirar con la más fría indiferencia la ilustración, el adelantamiento y los verdaderos intereses del Perú. No se diga ya en adelante que nuestro clima afeminado es el que nos detiene en el ocio, y nos ha conducido a una total insensibilidad hacia los grandes proyectos". ${ }^{45}$

En todo momento, la intención de El Peruano fue convertir la opinión pública en un tribunal tanto o más legítimo que el mismo virrey ${ }^{46}$ Las innumerables cartas al editor que generó la lectura de los debates acerca de la libertad de publicar y leer confirmaba tal propósito. Un lector de $E l$ Peruano confesaba haber seguido con gusto los debates publicados sobre la libertad de imprenta en Cádiz, pero decía no entender si esa libertad facultaba a la población a leer todo tipo de papel. Los editores, sin recurrir al parecer del virrey, le respondieron que nada servía peor al proyecto de la ilustración de la opinión pública que una lectura limitada. La difusión del hábito de leer era absolutamente recomendable, siempre y cuando "veneremos nuestra santa religión y las leyes fundamentales del reyno, respetemos las buenas costumbres...(ya que) la lectura de escritos que hieren a la divinidad, es aborrecida de la nación, y no está tampoco permitida". ${ }^{47}$ Otro lector, que decía estar "tocado de la comezón de hablar y escribir", pre-

44 El Peruano, núm. 15, Lima, viernes 25 de octubre de 1811.

45 Ibídem, núm. 4. Lima, martes 17 de septiembre de 1811.

46 Sobre la emergencia de la opinión pública como contrapeso de la autoridad absolutista, ver Baker, Keith Michael: "Politics and Public Opinion under the Old Regime: Some Reflections" en Censer, Jack R. y Popkin, Jeremy (eds.): Press and Politics in Pre-Revolutionay France. Berkeley, 1987, pág. 213.

47 El Peruano, núm. 12. Lima, martes 15 de octubre de 1811. 
guntó a los editores si convenía que ellos conociesen al autor de un escrito como ordenaba la ley de imprenta. El mismo confesaba temer a la autoridades y, por eso, preguntaba a los editores si revelarían su nombre en caso de ocurrir la censura de un artículo que pensaba remitir:

“(...) me parece que ya oigo decir a U. con mucha entereza que no cometerá semejante crimen. Si quien pregunta es el Santo Oficio, o el superior gobierno ¿tendrá U. la misma firmeza? ¿No temerá U. las casas matas, o los calabozos del santo tribunal?”. ${ }_{48}$

En varios números de El Peruano, Gaspar Rico, que escribió bajo el seudónimo de "El Invisible", aseveró que la plena vigencia de la libertad de imprenta era la única manera de garantizar el destierro del despotismo en el virreinato. Fiel a esa consigna, el periódico se reafirmó en su intención de seguir insertando cualquier escrito, sin otra responsabilidad que reservar el nombre de su autor, para manifestarlo en caso de declarársele infractor de la ley ${ }^{49}$ El Peruano, incluso, en su propósito de ampliar el espacio para la opinión anunció estar dispuesto a imprimir "todos los papeles que lleven los pobres de todas clases, a quienes podrá servir de consuelo el que se oigan o manifiesten sus desgracias". ${ }^{50}$

Un total de cuatro expedientes de censura se abrieron en contra de $E l$ Peruano mientras éste circuló como defensor de la autoridad del "público". El primer proceso en que se vio comprometido fue por oponerse a la censura de dos manuscritos del brigadier Manuel Villalta, el segundo expediente se le abrió por publicar un artículo de Miguel Eyzaguirre que abogaba por la abolición del tributo, el tercero fue interpuesto por Pedro Abadía por habérsele calificado de extranjero y, el último, por sospecharse su vinculación con El Satélite del Peruano. ${ }^{51}$ La Gaceta del Gobierno de Lima, por su parte, hizo de El Peruano el blanco de sus ataques, sobre todo cuando se halló en sus artículos un cuestionamiento a la autoridad del virrey. En una de esas ocasiones, el diario de Abascal publicó la carta de Juan de Atalayuela en contra de Gaspar Rico por declamar "que estamos rodeados de franceses y agentes de Napoleón, y aunque hay regimiento de Concordia, no hay concordia en esta capital". ${ }^{52}$ El Peruano replicó que lo único que hacía era asumir la defensa de los derechos de los ciudadanos a expresarse y formarse una opinión propia porque, de no hacerlo, “¿de qué

48 Ibídem, núm. 15, Lima, 25 de octubre de 1811.

49 Ibídem, núm. 16, martes 29 de octubre de 1811.

50 Ibídem, núm. 22. Lima, martes 19 de noviembre de 1811.

51 Martínez Riaza: La Prensa Doctrinal..., págs. 104-106.

52 Suplemento a la Gaceta del Gobierno, sábado 18 de enero de 1812. 
deberían ocuparse unos hombres que jamás tuvieron el derecho no sólo de escribir, pero ni aun de hablar lo que sentían, sino de los infinitos abusos de que habían sido víctimas por largo tiempo?". Ilustrar a la opinión pública significaba, ante todo, romper con "los defectos de nuestra educación y la falta de costumbre de hablar ante el público". ${ }^{53}$

Para los editores de El Peruano, en el ciudadano estaba arraigada la sumisión absoluta a la autoridad como resultado de las prácticas sociales interiorizadas por el absolutismo borbónico. En consecuencia, el periódico debía imponerse la tarea de incentivar una pedagogía política, basada en inculcar a los lectores la defensa de sus derechos civiles ante la arbitrariedad de una autoridad. Esta búsqueda de una nueva forma de inserción de los vecinos a la vida pública explica la confrontación entre el periódico y el virrey, quien se convirtió en baluarte de la causa absolutista. La nueva pedagogía política que El Peruano aspiraba a inculcar en sus lectores combinaba las definiciones moderna y antigua de la libertad. Efectivamente, en algunos de sus artículos los derechos del ciudadano, a los que se hace constante alusión, aparecen secundados por la recuperación de una libertad conforme al derecho natural.

La opuesta visión de los derechos y la política que tenían El Peruano y el virrey, se volvió tirante a raíz del debate que generó la publicación de dos obras del brigadier Manuel Villalta. Ambos escritos estaban dirigidos al Cabildo de Lima y solicitaban el reconocimiento al general José Manuel de Goyeneche por su triunfo en Guaqui sobre las tropas bonaerenses. Pero la imprenta de los Huérfanos, en septiembre de 1811, interrumpió la edición de los manuscritos al prohibírselo la Junta de Censura. La censura a los manuscritos de Villalta fue el pretexto usado por el virrey para expresar a la Regencia su disconformidad con el uso de la libertad de imprenta porque, en su opinión, afectaba la seguridad del gobierno. Abascal describió los manuscritos como unos de los muchos escritos perturbadores del orden que presuponían "que los españoles americanos han estado encorvados y oprimidos". ${ }^{54}$ Gaspar Rico, que leyó los manuscritos de Villalta antes de entrar en imprenta, asumió su pública defensa al considerar que una ley de carácter natural la amparaba:

“(...) yo he leído diez veces su papel y nada le encuentro censurable si nos atenemos al sentido natural del decreto de las Cortes". ${ }^{55}$

53 El Peruano Extraordinario, núm. 35, Lima, martes 31 de diciembre de 1811.

54 Medina: Historia de la Imprenta..., pág. 31.

55 El Peruano, núm. 14; Lima, 22 de octubre de 1811. 
Era evidente que Gaspar Rico se refería a la ley de imprenta bajo la ecléctica frase de una "libertad reglada por exaltar sus derechos en la naturaleza".

La censura trascendió a la opinión pública al ser abordado el caso Villalta de distinta manera por parte de El Peruano. Unas veces recurriendo a la sátira, como cuando se publicó la carta remitida por Paula Adellqueta "mujer legítima de la libertad de imprenta (que) ha oído que la defensa del Sr. Villalta anda en curso; y procurando el alivio de su marido en este continente, o ir al otro por si lo cura, espera el aviso de lo que resulte en el Peruano". ${ }^{56}$ Otras veces, prefiriendo el tono serio, haciéndose llegar al lector el dictamen en minoría de la Junta Censora de la Libertad de Imprenta, que consideraba que "las expresiones del señor Villalta apenas son una débil repetición de las que se escriben, publican y circulan con más enardecimiento en España..._por qué condenar en Lima lo que circula libre, no sólo en España sino en todos los rincones de la América?...En último análisis quiere decir esto que la imprenta de los Huérfanos de Lima envenena unas proporciones que han salido sanas y buenas de las de Cádiz, Madrid, Sevilla, etc. y andan esparcidas en todo el continente americano". ${ }^{57}$

Cabe destacar que la guerra verbal que originó el caso Villalta se amplió a otro espacio ajeno a El Peruano: el de los impresos. La polémica comenzó con la defensa de sus manuscritos que mandó editar el propio Manuel Villalta a fines de 1811. Allí, Villalta afirmaba que su intención al querer publicar los manuscritos censurados había sido ver reflejado en el homenaje público de un "ilustre americano", el general Goyeneche, las glorias que a él se le habían negado con ocasión de la derrota de Tupac Amaru II por su condición de criollo. El remordimiento que, desde esa época, Villalta acumuló contra el despotismo español le hizo convertirse en un fanático defensor de la libertad de imprenta, ya que ésta asumía como uno de sus fines desterrar el despotismo del que él se consideraba una víctima. Para Villalta era indispensable que el pueblo saliera de su pasividad ante la autoridad, y que la imprenta le apoyara a distinguir los delitos provenientes de una tiranía. De no ocurrir de ese modo, la contienda estaría ganada por "Los Príncipes que se aplauden de mantener a su nación en un profundo adormecimiento, (que) entienden mal sus intereses....".58

56 El Peruano, núm. 16; Lima, 29 de octubre de 1811.

57 Ibídem, núm. 32, Lima, 19 de diciembre de 1811.

58 Breves reflexiones sobre la censura de los oficios dirigidos al Excmo.Ayuntamiento de esta capital por el brigadier Don Manuel Villata del orden de Santiago, escritas por él mismo. Lima, 1811, pág. 13. 
Meses después, comenzó a circular por Lima un folleto redactado por Verísimo Cierto, donde se calificaba de peligroso y subversivo el fervor con que en su impreso Villalta asumía la defensa de los derechos del pueblo, porque "la experiencia ha acreditado con innumerables y dolorosos hechos, repetidos por todas partes de ambas Américas, el abuso criminal que se ha hecho de la libertad reglada por exaltar sus derechos con la naturaleza". ${ }^{59}$ La carta de Verísimo Cierto conducía la discusión al complicado terreno del tipo de libertad acerca del que discutían Villalta y El Peruano. En efecto, en muchos momentos a Verísimo Cierto le parecía que estos dos polemistas centraban su atención sobre la conveniencia de la restitución de una justicia antigua, la que demandaba el bien común, pero en otros apartados también hacían expresa mención a una libertad basada en los derechos del ciudadano. La circulación de otra carta que continuaba la polémica en torno a Villalta, esta vez dirigida por Metafórico Claros a Verísimo Cierto, tampoco contribuía a aclarar esta confusa visión de la libertad. Metafórico Claros asume la defensa de Villalta en su derecho de reclamar contra la arbitrariedad porque " iqué resultados trae consigo la vilísima servidumbre de agradar a los grandes por el interés de ese humo instantáneo, que se llama gloria! ¡Ella hace perder al hombre la primera bendición del cielo que es la libertad!". ${ }^{60}$ De esta discusión únicamente quedaba en claro que los constitucionalistas aunque sabían que su oponente era el despotismo, tenían muchos problemas para precisar la identidad de la nueva expresión que buscaban. No tuvieron oportunidad de hacerlo. El debate culminó con la aprobación de la censura de los textos de Villalta y la posterior clausura de El Peruano.

El Satélite del Peruano, que apareció entre marzo y junio de 1812, se impuso la misión de secundar las ideas políticas de El Peruano. En el proyecto de edición del nuevo papel, estuvo inicialmente comprometida una Sociedad Filantrópica que debía ocuparse de la redacción de los artículos de Política, de Literatura y de Ciencia. Pero al ser censurado el prospecto del periódico aparecido en marzo, la tertulia prefirió disolverse. Para Fernando López Aldana, el único tertuliano que decidió continuar la empresa, la actitud tomada por los miembros de la Sociedad Filantrópica era lamentable ya que daba la razón a quienes expresaban reparos para escribir por temor a la autoridad:

59 Carta de Don Verísimo Cierto a un condiscípulo suyo, sobre las reflexiones del señor Villalta a la censura de sus oficios dirigidos al Excmo.Ayuntamiento de esta capital. Lima, 1812, pág. 16.

60 Carta de Don Metafonio Claro a Don Verísimo Cierto. Lima, 1812, pág. 2. 
“(...) los efímeros socios con su retractación, sin haber contribuido un ápice al beneficio de su país nada más han logrado que cargar el peso enorme del general descrédito, en lugar del honor que les estaba preparado si se hubieran sostenido noble y firmemente en un comportamiento tan virtuoso, tan útil, tan honorífico" ${ }^{61}$

La circulación de El Satélite fue considerada por Abascal como mucho más peligrosa que la de su antecesor, por su insistencia de que en el Perú no se cumplía la libertad de imprenta, calificándose a la Junta de Censura de "viciosa". El Satélite, además, publicó un artículo bajo el título de "Derechos del hombre", en donde se concluía que los nuevos derechos políticos afianzaban la igualdad entre españoles y americanos. ${ }^{62}$ Esta reflexión, que hubiera contribuido a aclarar la postura política de los constitucionalistas, fue, abruptamente, cortada en junio, al dejar de circular $E l$ Satélite por orden del virrey.

Los intentos del gobierno por silenciar a El Peruano y a El Satélite no pudieron impedir que el discurso constitucionalista invadiera otros espacios públicos. En estos casos, dicha conquista se presentaba como el resultado de un duro enfrentamiento entre el empeño de las autoridades en sostener su arbitrariedad y la libertad de publicar las ideas. Un ejemplo fue la publicación en El Peruano de la carta de un lector oculto bajo el seudónimo de "Claudio Dudas", quien contó que un día había visto "dándose de mojicones a unos muchachos por haberse roto entre ellos unas listas de toros pequeñas, y que tenían por mote viva la libertad de imprenta. Había varios partidos sobre el hecho: éste decía que no podían venderse más listas que las de a pliego, que estaban con privilegio, que éste era un derecho exclusivo al impresor de ella, etc; el otro, que había libertad de imprenta, y que Perico el de la esquina podía imprimir y vender listas". ${ }^{63}$

El gobierno de Abascal enfrentó a los partidarios de una postura política contraria al absolutismo, reestructurando la retórica fidelista que supuso interiorizar en el adversario la invulnerabilidad de la autoridad. Esta retórica política, a diferencia de la practicada anteriormente, perseguía los propósitos de mantener, por un lado, la lealtad de la población a Fernando VII y las Cortes de Cádiz y, por otro lado, hacer interiorizar a los ciudadanos la absoluta necesidad de cultivar la lealtad para con el virrey. Un ejemplo del primer caso fue la invitación que la Gaceta hizo para que todo aquél

61 El Satélite del Peruano, núm. 1; Lima, marzo de 1812.

62 Martínez Riaza: La Prensa Doctrinal..., págs. 34-35.

63 El Peruano, núm. 31, Lima, martes 17 de diciembre de 1811. 
que tuviera un escrito fidelista dedicado a la jura de la Constitución en Lima, lo remitiera de inmediato al diario:

“(...) esperamos que las bellas plumas de esta capital se exerciten en presentar al mundo entero cuanto haya de notable en esta fiesta que será sin duda de las más admirables". ${ }^{64}$

De otro lado, abundaron los ejemplos por intentar mantener la concordia en torno al virrey, caracterizándose todos estos discursos por lanzar duros ataques a los escritores que reclamaban un nuevo trato entre españoles y americanos:

“(...) americanos españoles que continuais denigrando en nuestros periódicos el nombre español ¿habéis perdido enteramente la moderación, la gratitud, el pudor? Vosotros os abomináis de llevar en vuestras venas la sangre que os dé la vida que tenéis, en otros climas se creen los hombres invencibles y dichosos con tener amigos españoles solamente. Callad, pues, desconocidos, aprended en adelante a ser severos ciudadanos" ${ }^{65}$

El proyecto más importante del virrey para refrenar la pedagogía política alentada por los anti-absolutistas se puso en marcha el 22 de septiembre de 1812. Ese día, la aparición de El Verdadero Peruano, convertía en realidad el sueño de Abascal de lanzar la segunda época del Mercurio Peruano. Tal intento de imitar el mejor momento del despotismo ilustrado, comenzó con la conversión del virrey en protector de la nueva publicación. Los editores, el presbítero Tomás Flores y José Pezet, manifestaron que la tertulia literaria que tenía la responsabilidad de editar El Verdadero Peruano, se imponía la tarea de promover la ilustración general en concordancia con la autoridad virreinal. A este diario volvieron las reflexiones de los Filópatros, Aristios y Filaletes y las extensas disertaciones sobre Geografía, Historia, la condición del indio y el estado del comercio característicos del viejo Mercurio Peruano. Las veces que se impuso el abordaje de un tema político, se hizo consultando previamente el parecer del virrey. Así ocurrió con el discurso político de Filópatro en homenaje a la Constitución y también en los temas relacionados con la educación.

Uno de los problemas públicos más importantes que $E l$ Verdadero Peruano se impuso abordar era el modo en que debía promoverse la educación popular bajo el espíritu de la constitución. El debate fue inaugurado

64 Gaceta del Gobierno de Lima, núm. 76; Lima, 26 de septiembre de 1812.

65 Ibídem, núm. 110; Lima, 28 de diciembre de 1812. 
por Félix Devoti a través de su artículo "Amor a la Patria, a la Constitución y al Rey", donde señalaba que la educación nacional era el primer objetivo de una sociedad bien educada y con la cual se preparaba el espíritu público. ${ }^{66}$ Otro articulista reconocía que la ilustración y el conocimiento de los derechos del hombre eran imprescindibles en una sociedad que aspiraba al bien común. ${ }^{67} \mathrm{~A}$ pesar de ambas afirmaciones, en el ensayo donde se perfiló el nuevo proyecto educativo, se omitió toda referencia a la enseñanza de los derechos del hombre. En la superación de la ignorancia bastaba con formar escuelas regentadas por religiosos donde se "enseñe a los niños a leer, escribir y contar, y el catecismo de la religión católica, que comprehenderá también una breve exposición de las obligaciones civiles". ${ }^{68}$ Este periódico dejó de salir el 26 de agosto de 1813, afectado por una crisis económica y falta de subscriptores.

Fue en medio de una aguda crisis económica, provocada en Lima por el intento de Abascal de recuperar la capitanía general chilena, cuando de nuevo Guillermo del Río pone en marcha el plan de editar un diario, esta vez distinto a cuantos hasta entonces se habían publicado. El diario debía acomodarse a las críticas circunstancias que experimentaban los lectores limeños, por lo cual se fijó su costo en apenas un real, ofreciendo a cambio "facilitar el giro doméstico y comunicar con brevedad y exactitud las ocurrencias de Lima". ${ }^{69}$ Con la puesta en circulación de El Investigador, el 1 de julio de 1813, la lectura exclusiva de la noticia local vino a imponerse como una moda de éxito rotundo entre los lectores.

Con El Investigador, Guillermo del Río esta vez puso extremo cuidado en no provocar las iras del virrey. Sorprendentemente, Del Río refrendaba ahora el discurso oficial que denigraba las lecturas puestas en circulación al amparo de la libertad de imprenta. Su balance sobre el significado de la lectura en el fomento de la ilustración del público limeño no podía ser más negativo:

“(...) el odio, la venganza, la sátira mordaz y soez, abortaron producciones pueriles y detestables. El bello sexo, digno de aprecio y respeto, se vio vilmente ultrajado en los versos denigrantes de un poetastro inmoral, indecente y mercenario; impugnaciones ridículas y mal sazonadas inundaron la capital y sólo sirvieron a manifestar el abuso que se hacía de un bien que acababan de conceder las Cortes". ${ }^{70}$

66 El Verdadero Peruano, t. I, núm. 9, Lima, 18 de noviembre de 1812.

67 Ibídem, t. I, núm. 3; Lima, 8 de octubre de 1812.

68 Ibídem, t. I, núm. 24; Lima, 4 de marzo de 1813.

69 Medina: La Imprenta en Lima..., t. 3, pág. 118.

70 El Investigador, t. III, núm. 45, Lima, 25 de julio de 1813. 
Aunque para El Investigador continuaba siendo indispensable la tarea de la ilustración popular, el mal uso del libre pensamiento mostraba que antes se requería de una sólida infraestructura educativa para impulsarla. La supresión de la Inquisición, ordenada por Abascal en septiembre de 1813, se presentó como el momento oportuno para abordar el tema de la educación popular.

El Investigador festejó con algarabía la abolición del Tribunal del Santo Oficio. De inmediato, el diario inició una campaña para que el edificio de esta institución se transformara en un espacio abierto al público, proponiendo que allí se habilitara la primera biblioteca pública de la ciudad. El Investigador retomaba así el viejo plan de Llano Zapata de 1758, proponiendo al gobierno igualmente asumir la protección del nuevo establecimiento. La biblioteca pública, señalaba El Investigador, debería instalarse en la antigua sala de sesiones de la Inquisición, y su entrada podría dar a la plazuela para que "todo el pueblo vea si se cumple o no se cumple por los encargos de ella". Asumiendo que la existencia de una biblioteca bien surtida y atendida era vital en la campaña de procurar la ilustración popular, el diario propuso trasladar a las estanterías de la biblioteca pública "la librería del fraile Diego Cisneros y los restos de la biblioteca (de San Marcos) que dejó arruinar, robar y malograr la indolentísima conducta y abandono con que se ha mirado en la universidad éstas". ${ }^{11}$ El Investigador, asimismo, prometió iniciar una campaña para que la biblioteca se abasteciera con donaciones provenientes de bibliotecas particulares. El diario auguraba que con la habilitación de la biblioteca pública se podría hasta evitar que los libros volvieran a ser mal usados, ya que "no irán a pasar a las boticas para envolver ungüentos, ni a los cajones de ribera para enrollar especerías, o a otras manos como ha sucedido con tanto inestimable libro que se dio por el rey a la universidad". ${ }^{22}$

La campaña que en favor de la difusión del libro había iniciado $E l$ Investigador, fruto de su entusiasmo por ver extinguida la Inquisición, continuó en números siguientes, aunque esta vez motivada por un problema distinto. Efectivamente, el diario llegó a la conclusión de que, desaparecida la Inquisición, ahora era un sector de la plebe el enemigo principal de la conservación y lectura de los libros al traficar con su venta como envoltorios de especerías. Dicha campaña de protección del libro comenzó con denuncias de este estilo:

71 Ibídem, núm. 61; Lima, 30 de agosto de 1813.

72 Ibídem. 
“(...) que en el quartel 1, no. 6, el mes de noviembre encontró el sereno a un negro en alta noche con unos libros que los había robado, de quien fuesen dando las señas de las obras que son por el alcalde de este quartel, se le entregarán". ${ }^{73}$

La obsesiva vinculación de la plebe con el tráfico del libro para su uso como envoltorios, se expresa a través de la carta de un lector oculto bajo el seudónimo de "Un Librero lastimado de estos hurtos". Éste clamaba por un remedio para contener el sistemático robo de libros que de modo continuo se registraba en el convento de los Descalzos. La reflexión comenzaba con el recuento de uno de esos tantos robos. Un sábado por la tarde "se introdujo por una ventana a la celda del padre Fray Pablo Rosas un zambo achinado...que formó un quipe de libros de dicho padre y de otro religioso que los dio a guardar, temeroso de no experimentar segunda extracción". Aunque el ladrón fue sorprendido por ambos frailes, logró fugarse hacia la huerta de Palomares y del Altillo donde sus cómplices lograron esconderlo. Ambos lugares, señalaba el "Librero lastimado", eran desde hacía mucho tiempo el centro de un gran tráfico de libros robados. La plebe desde allí trasladaba los libros "al panteón de los cajones de Ribera y pulperías, donde se deshojan para envolver especerías y otras vendimias. Si no hubieran estos compradores los ladrones se abstendrían de tomar libros". El "Librero lastimado" proponía como remedio prohibir a las pulperías y cajones la compra de libros a la plebe, redoblando la vigilancia de los serenos para decomisar los que se encontrasen "porque de no, a la larga o a la corta, acabarán con las librerías; pues causa lástima ver las obras truncas". ${ }^{74}$

La asociación de la plebe con el tráfico de los libros hurtados fue objeto de otro artículo, esta vez escrito en un tono satírico. Un lector informó a El Investigador que, luego de ver cruzar por la plaza a un hombre que llevaba unos libros para su venta en los cajones de Ribera, se avalanzó sobre él y halló entre los libros una Disertación sobre la impropiedad con que se ha dado siempre a la Inquisición el nombre de santa y también El modo de ganar dinero en poco tiempo y sin trabajo ${ }^{75}$ entre otros títulos más.

Ni la campaña emprendida para la formación de la biblioteca pública ni la persecución verbal de la plebe pudieron continuarse, debido a que $E l$ Investigador dejó de circular el 31 de diciembre de 1814 por orden de Abascal. El virrey, en efecto, recibió una disposición que suspendía la

73 Ibídem, núm. 46; Lima, 16 de diciembre de 1813.

74 Ibídem, t. IV, núm. 25; Lima, 4 de agosto de 1814.

75 Ibídem, núm. 17; Lima, 17 de diciembre de 1813. 
libertad de imprenta casi al culminar 1814, medida con la que al mismo tiempo se restablecía la ley de imprenta de 1805 . La orden fue ejecutada tan abruptamente que en el Perú ya no existían periódicos cuando Fernando VII, en mayo de 1815, prohibió su publicación tanto en España como en América. El 22 de marzo de 1816, el rey ordenaba recoger todos los catecismos políticos y religiosos editados bajo el interregno liberal. ${ }^{76}$ Ninguno de los cinco catecismos políticos mencionados en la censura circulaban ya por Lima. La capital peruana había entrado en una etapa de un progresivo silencio político. En 1815 la impresión de folletos políticos languideció, al contarse apenas cinco impresos de este tipo, todos fidelistas, frente a 23 de contenido religioso. En 1816 dicha desproporción se amplió a sólo un texto fidelista contra 18 de contenido religioso. La práctica de la lectura volvió a tornarse monótona y, junto con la pedagogía política, sólo retornó al debate público después de la independencia.

\section{Conclusión}

La transformación del hábito de lectura en Lima adquirió un primer impulso con la puesta en circulación de tres periódicos en la primera mitad de la década de 1790: el Diario Erudito, el Mercurio Peruano y el Semanario Crítico. De estos tres, fue el Mercurio Peruano el proyecto más importante porque su publicación culminaba el deseo de los virreyes ilustrados de promover una selecta opinión pública literaria. Quienes escribieron en el Mercurio Peruano pusieron todo su empeño en ampliar el conocimiento del país en favor del proyecto ilustrado del virrey Gil. Este vínculo de reciprocidad entre la autoridad despótica y la Sociedad de Amantes del País, explica el escaso interés puesto por el Mercurio Peruano en fomentar una corriente de opinión más allá de lo científico y lo literario.

El segundo momento en la transformación de la lectura en la capital peruana se produjo después de confirmarse en agosto de 1808 la invasión de la metrópoli por las tropas francesas y la posterior insurrección española. Por vez primera, Lima se vio inundada de folletos políticos fidelistas con los que el gobierno del virrey Abascal pretendió mantener la lealtad de la población a Fernando VII. Inédito fue igualmente que el diario oficial, la Minerva Peruana, convirtiera tal tipo de propaganda política en su cometi-

76 Torre Revello: El Libro, la Imprenta y el Periodismo..., pág. CCXXXIV. 
do principal. La retórica fidelista inclusive se manifestó en las entradas de los cafés y en el teatro. Esta fulgurante difusión de la lectura fidelista introdujo a una amplia capa de la población, vinculada con la aristocracia, en el conocimiento de temas públicos y políticos de los que hasta entonces habían estado celosamente marginados. El mismo virrey Abascal se encargó de la interrupción de este avance de la lectura política, al advertir los peligros que ella podía representarle, en caso de proseguir el éxito de la insurgencia que ya habían promovido las juntas tuitivas de Buenos Aires, Chile y Quito.

Finalmente, el tercer gran avance de la lectura en Lima ocurrió cuando se dio plena vigencia a la libertad de imprenta decretada por las Cortes de Cádiz. A través de dos periódicos - El Peruano y El Satélite del Peruano- y algunos impresos, se trató de inculcar al público lector la defensa de sus derechos civiles en contra de la arbitrariedad con que actuaban las autoridades virreinales. Esta nueva retórica política anti-despótica causó la mortificación del virrey Abascal, que no dudó en calificarla de subversiva y de sumo riesgo para la seguridad de su gobierno. El tono contestatario de los escritos en contra del despotismo fue, inmediatamente, silenciado con el cierre de El Peruano y El Satélite y la censura de algunos folletos que se interpretaban como afines a aquel discurso político antiabsolutista. El temor a la autoridad que el gobierno de Abascal intentó seguir inculcando bajo el clima de la libertad de imprenta tuvo un éxito relativo. Ello se reflejó en el discurso escasamente político y, sobre todo, sumiso al virrey, que impregnaron sus editores al último diario no oficial: El Investigador.

No obstante, fue en la tercera fase del avance de la lectura cuando la pedagogía política hizo su aparición en la sociedad limeña. A través de las discusiones alentadas por Guillermo del Río, Gaspar Rico y Manuel Villalta acerca del nuevo trato que debía existir entre ciudadanos y autoridades, afloró la necesidad de promover nuevas interrelaciones sustentadas en un criterio ecléctico del concepto de libertad, donde lo único claro fue la oposición a la continuidad del despotismo. Esta postura política fue definitivamente suprimida por Abascal a fines de 1814, amparado esta vez en la Restauración absolutista. 